\title{
A study on health-related quality of life and co-morbidity among elderly population in rural Sabah, Malaysia
}

\author{
Thant Zin ${ }^{1}$, Than Myint ${ }^{2}$, Daw K. S. Naing ${ }^{3}$, Kyaw Htay ${ }^{4}$, Aye Aye Wynn ${ }^{5}$, Tin SabaiAung ${ }^{6}$, Awang Setia \\ Bin Musleh ${ }^{7}$, Fredie Robinson ${ }^{8}$
}

${ }^{1}$ Former Senior Lecturer; ${ }^{3}$ Associate Professor, Community and Family Medicine; ${ }^{2}$ Head, Rural Medicine Research Unit; ${ }^{4}$ Former Associate Professor, Surgical Base Department; ${ }^{5}$ Senior Lecturer; ${ }^{6}$ Associate Professor, Pathobiology and Diagnostic Department, ${ }^{7}$ Deputy Dean, Faculty of Medicine and Health Science; ${ }^{8}$ Director, Community Treatment Centre; University Malaysia Sabah, Kota Kinabalu, Sabah, Malaysia.

\section{Abstract}

Ageing is a global phenomenon. In Malaysia, a projected model estimated that the number of elderly would be 3.4 million in 2020 which is more than $10 \%$ of the population. A cross-sectional study targeted the elderly population of three villages in rural Sabah, Malaysia aimed to investigate the health-related quality of life, comorbidity, and the socio-demographic profile amongst the elderly in the community. Participants (60 years and above) were selected for face-to-face interviews using health-related quality of life questionnaires (SF-36). SPSS 21 was used for statistical analyses. Results showed that mean (sd) of age; 67.71 (6.95) years. Five common co-morbidities were hypertension $(67 \%)$, bone and joint pain $(63 \%)$, gastric pain $(67 \%)$, poor vision $(58 \%)$, and hearing problems $(33 \%)$. The highest HRQoL score was social functioning (67.96) whereas the lowest HRQoL score is role limitation due to emotional problems (30.54). There is a significant relationship between HRQoL domains and socio-demographic factors (gender, marital status, membership in association), and health condition (co-morbidities and access to healthcare, bone and joint pain or arthritis and treatment, hearing impairment and treatment) which indicated need for health and social support like participating in association and access to health care for rural elderly in future programme. We recommend a further study to compare elderly HRQoL in rural, urban and institutional settings for future health-care planning.

Keywords: Elderly, Health-Related Quality of Life, Co-morbidity, Rural Sabah, Malaysia.

\section{Introduction}

Ageing is a global phenomenon. With tremendous improvement in global health, people live longer; however, it poses special challenges for the $21^{\text {st }}$ century. In 2011, life expectancy in countries like Japan and Switzerland was already more than 82 years. ${ }^{1}$ Countries' health systems around the world are burdened with increasing health care expenditures for ageing populations. In Malaysia, a projected model estimated that the number of elderly would reach 3.4 million in 2020 , which is more than $10 \%$ of the population. ${ }^{2}$

The ageing process is a multi-complex phenomenon encompassing many consequences, such as impairment of body functions, higher morbidity, decreasing autonomy and need of care. ${ }^{1}$ Therefore, there is a need for comprehensive health support for the elderly and integrated systems that provide universal access to care for the needy.

The World Health Organization (WHO) is promoting Active Ageing, a process of optimizing opportunities for health, participation and security in order to enhance quality of life as people age. ${ }^{3}$ For example, the theme of the 2012 World Health Day was 'Ageing and Health'.

Health related quality of life (HRQoL) is an essential tool

\section{Practice Points}

- In Malaysia, a projected model estimated that the number of elderly would be 3.4 million in 2020 which is more than $10 \%$ of the population.

- Five common co-morbidities among elderly were hypertension $(67 \%)$, bone and joint pain $(63 \%)$, gastric pain $(67 \%)$, poor vision $(58 \%)$, and hearing problems $(33 \%)$.

- The highest HRQoL score was social functioning (67.96) whereas the lowest HRQoL score is role limitation due to emotional problems (30.54).

- There is a significant relationship between HRQoL domains and socio-demographic factors, and health condition.

- The study highlighted need for health and social support like participating in association and access to health care for rural elderly in future programme.

in the evaluation of physical function and basic health to explore people's feelings about health and their understanding of social health. ${ }^{4}$ Quality of life (QoL) -

Correspondence: Dr Thant Zin, School of Medicine, University Malaysia Sabah, Kotakinabalu, Sabah Malaysia, 88450. Email: thantzinphdc@gmail.com. 
health and happiness - and HRQoL have been used by some treatment programs in the urban setting..$^{5-7}$ However, there is still limited knowledge on the ability of HRQoL to predict elderly peoples' mortality, morbidity and other adverse health events, especially in the rural areas of low and middle income countries.

The Health Status Questionnaire (SF-36), the most widely accepted generic health status measure and HRQoL measures, can evaluate various health dimensions and the impact of disease as well as benefits of treatment. ${ }^{4}$ It is a brief (36-item) scale developed from the Medical Outcomes Study (MOS) and reported in the International Quality of Life Assessment Project (IQOLA). ${ }^{8,9}$ It can also be used as a predictor of mortality; Tsay et al..$^{10}$ found a greater risk of mortality among those who scored low on the SF-36 measures. The Short Form-36 (SF-36) has proven to separate between different chronic conditions and different severity levels of the same disease in many clinical and research studies. ${ }^{11-12}$

This study aimed to investigate health-related quality of life, health-care utilization, socio-demographic and disease comorbidity among the elderly population of three villages in rural Sabah, Malaysaia.

\section{Materials and methods}

This study was a cross-sectional study conducted among the elderly population aged 60 years and above in three purposively selected rural villages of Tongod, Kinabatangan Sabah, Malaysia. The three villages were: $\mathrm{Kg}$ Linayukan, Tongodon and Simuda. Elderly was defined as individual aged 60 years and above, and referred to two studies undertaken in Malaysia: Selvaratnam et al. ${ }^{13}$ and Chen et al. ${ }^{14}$ The inclusion criteria were elderly who were not bedridden, and who did not have major psychiatric morbidity. All elderly who agreed to participate in the study were interviewed with a set of questionnaire which consists of: MOS (SF36), socio-demographic and co-morbidity questionnaires. There were 24 elderly participated in the study. The ethical permission of the study was granted by the Ethical Committee, School of Medicine, University Malaysia Sabah, Sabah State, Malaysia [JKEtica 2/13 (4)].

The MOS (SF-36) questionnaire contains a single item covering changes in health status over the last year which are reported by eight domains/dimensions with multi-item scales (health concept or component); physical functioning (PF: 10 items), role limitations relating to physical health (RP: 4 items), role limitations relating to emotional problems (RM: 3 items), energy fatigue (Vitality: 4 items), emotional well-being/mental health (MH: 5 items), social functioning (SF: 2 items), bodily pain (Pain: 2 items), and general health (GH: 5 items). ${ }^{12,15}$ Responses on items are recorded before being added to other items within the domains. Health survey items were constructed using the Likert method of summated ratings. ${ }^{16}$ Raw scores - (1-5) MSQLI/ Mean Score Quality of Life Index - are then transformed to a (0-100) scale by applying scoring algo- rithm (RAND Score). ${ }^{17-19}$ Answers to each question are scored and summed to produce raw scores for each health concept which are then transformed to a $(0-100)$; higher values indicate better-perceived health. ${ }^{20}$

The (SF-36) questionnaire is a validated, generic selfadministered questionnaire. ${ }^{21-22}$ As evidenced from many studies among older adults, the SF-36 has demonstrated high reliability (Chronbach's alpha, 0.72 to 0.94 ), construct validity and convergent validity. ${ }^{23-24}$ Both English and Malay versions are available. However, the elderly in the study area had a lower literacy rate, poor reading capacity and some vision problems limiting them to being able to answer self-reported questions correctly. To minimize the effects of these limitations, our study used face-to-face interviews. Medical students were trained to collect face-to-face interview questionnaires on HRQoL.

Socio-demographic questionnaires including age, gender, education, marital status, drinking alcohol, smoking and membership in association, and comorbidity questionnaires which was adapted from economic well-being and morbidity of the elderly in Malaysia study. ${ }^{13}$ The questionnaire used to record twelve common co-morbidities and treatment namely hypertension, diabetes, heart disease, bone and joint pain or arthritis, cancer, asthma, gastritis and gastric pain, tuberculosis, stroke related, visual and hearing problems were asked and relevant finding were reported.

In statistical analysis, descriptive statistics was analysed for socio-demographic, co-morbidity and healthcare utilization, and HRQoL domains and reported for frequency and percentage for categorical data and mean and standard deviation for continuous data. Furthermore, univariate analyses were done for HRQoL domains and independent variables: socio-demographic, co-morbidity, and access to treatment. Because of small sample size, we used non-parametric test and any differences between groups for HRQoL scores were reported if $p$-value was $<0.05$. Socio-demographic variables were gender (male/female), education (illiterate/basic/higher), marital status-currently living with spouse (yes/no), smoking (current smoker/not) and membership in association (yes/no). In terms of comorbidity and disease status, ${ }^{13}$ reported positive answers for hypertension, diabetes, heart disease, bone and joint pain or arthritis, asthma, ulcer/gastric pain and gastritis, vision problems, hearing impairments and other non-specific diseases were used and calculated to derive the five most common co-morbidities among respondents. Treatment of co-morbidity was asked for treatment yes or no for all elderly answered for disease yes. We did not asked for more detail about disease and treatment such as duration, frequency and treatment category.

\section{Results}

In the study, the mean age of elderly was $67.71( \pm 6.95)$ years; male $67.14( \pm 6.51)$ years, and female 67.94 $( \pm 7.3)$ years. Other socio-demographic factors among 
Zin et al. - Health-related quality of life and co-morbidity among rural elderly

elderly were as follows: i) $95 \%$ of elderly were illiterate; ii) all male elderly and half of female elderly were currently not living with spouse; iii) $71 \%$ of male and $94 \%$ of female were currently non-smoker; and iv) only $29 \%$ of male and $6 \%$ of female were participating in association and social activity (Table 1).

The study also reported the five most common disease co-morbidities for elderly which included: i) $71 \%$ male and $65 \%$ female had hypertension while $60 \%$ of male and $91 \%$ of female patients were already treated; ii) $43 \%$ of male elderly and $71 \%$ of female elderly were suffering bone and joint pain/arthritis but one-third of male patient and most of female patients received treatment; iii) gastric pain/gastritis found among $43 \%$ of male and $77 \%$ of female while two-third of patients received treatment; iv) one-third of male and two-third of female elderly suffered poor vision; however, only

Table 1: Socio-demographic characteristics of respondents

\begin{tabular}{|c|c|c|c|}
\hline Categories & Male $(\%) n=7$ & Female $(\%) n=17$ & Total $(\%) n=24$ \\
\hline \multicolumn{4}{|l|}{ Education background } \\
\hline Illiterate & $6(86 \%)$ & $17(100 \%)$ & $23(96 \%)$ \\
\hline Basic & $1(14 \%)$ & $0(0)$ & $1(4 \%)$ \\
\hline \multicolumn{4}{|l|}{ Marital status } \\
\hline Currently living with spouse & 0 & $8(47 \%)$ & $8(33 \%)$ \\
\hline Currently not living with spouse & $7(100 \%)$ & $9(53 \%)$ & $16(67 \%)$ \\
\hline \multicolumn{4}{|l|}{ Membership in association } \\
\hline Yes & $2(29 \%)$ & $1(6 \%)$ & $3(13 \%)$ \\
\hline No & $5(71 \%)$ & $16(94 \%)$ & $21(87 \%)$ \\
\hline \multicolumn{4}{|l|}{ Smoking status } \\
\hline Current smoker & $2(29 \%)$ & $1(6 \%)$ & $3(13 \%)$ \\
\hline Non-current smoker & $5(71 \%)$ & $16(94 \%)$ & $21(87 \%)$ \\
\hline
\end{tabular}

Table 2: Five commonest co-morbidities among respondents*

\begin{tabular}{|c|c|c|c|}
\hline Comorbidity & Male $(\%) n=7$ & Female $(\%) n=17$ & Total $(\%) n=24$ \\
\hline \multicolumn{4}{|l|}{ Hypertension $(\mathrm{n}=24)$} \\
\hline No & $2(29 \%)$ & $6(35 \%)$ & $8(33 \%)$ \\
\hline Yes & $5(71 \%)$ & $11(65 \%)$ & $16(67 \%)$ \\
\hline \multicolumn{4}{|c|}{ Bone and Joint Pain/Arthritis $(\mathrm{n}=24)$} \\
\hline No & $4(57 \%)$ & $5(29 \%)$ & $9(37 \%)$ \\
\hline Yes & $3(43 \%)$ & $12(71 \%)$ & $15(63 \%)$ \\
\hline \multicolumn{4}{|c|}{ Ulcer/Gastritis/Gastric Pain $(\mathrm{n}=24)$} \\
\hline No & $4(57 \%)$ & $4(23 \%)$ & $8(33 \%)$ \\
\hline Yes & $3(43 \%)$ & $13(77 \%)$ & $16(67 \%)$ \\
\hline \multicolumn{4}{|l|}{ Vision Impairment $(\mathrm{n}=24)$} \\
\hline No & $5(71 \%)$ & $5(29 \%)$ & $10(42 \%)$ \\
\hline Yes & $2(29 \%)$ & $12(71 \%)$ & $14(58 \%)$ \\
\hline \multicolumn{4}{|l|}{ Hearing Impairment $(\mathrm{n}=24)$} \\
\hline No & $6(86 \%)$ & $10(59 \%)$ & $16(67 \%)$ \\
\hline Yes & $1(14 \%)$ & $7(41 \%)$ & $8(33 \%)$ \\
\hline
\end{tabular}

*Participants reported multiple responses

Table 3: Sub-analysis among elderly receiving treatment for the co-morbidities

\begin{tabular}{|c|c|c|c|}
\hline Treatment received & Male (\%) & Female (\%) & Total (\%) \\
\hline Hypertension with treatment $(\mathrm{n}=16)$ & & & $13(81 \%)$ \\
\hline Yes & $3(60 \%)$ & $10(91 \%)$ & $3(19 \%)$ \\
\hline No & $2(40 \%)$ & $1(9 \%)$ & $12(80 \%)$ \\
\hline Bone and Joint Pain/Arthritis with treatment $(\mathrm{n}=15)$ & & & $3(20 \%)$ \\
\hline Yes & $1(33 \%)$ & $11(92 \%)$ & $12(75 \%)$ \\
\hline No & $2(67 \%)$ & $1(8 \%)$ & $4(25 \%)$ \\
\hline Ulcer/Gastritis/Gastric Pain with treatment $(\mathrm{n}=16)$ & & & $4(29 \%)$ \\
\hline Yes & $2(67 \%)$ & $10(77 \%)$ & $10(71 \%)$ \\
\hline No & $1(33 \%)$ & $3(23 \%)$ & \\
\hline Vision Impairment with treatment $(\mathrm{n}=14)$ & & & $2(25 \%)$ \\
\hline No & 0 & $8(67 \%)$ & $6(75 \%)$ \\
\hline Hearing Impairment with treatment $(\mathrm{n}=8)$ & $2(100 \%)$ & & \\
\hline Yes & 0 & $2(29 \%)$ & \\
\hline No & $1(100 \%)$ & $5(71 \%)$ & \\
\hline
\end{tabular}

South East Asia Journal of Public Health 2015;5(2):35-42 
one-third of female patients were treated; and v) $14 \%$ of male and $41 \%$ of female elderly suffered hearing impairment but only one-third of female patients received treatment (Table 2 and 3 ).

Regarding HRQoL, male elderly scored higher than female elderly for all eight components. The three highest scores for male elderly were SF 84.14 , PF 78.57 and MH 74.29, and the three lowest scores for female elderly were Pain 36.76, RP 29.41 and RM 17.65. Mean score for both sex, male and female elderly for HRQoL domains were: PF 55.21 (male 78.57, female 49.59), RP 32.29 (male 39.29, female 29.41), RM 30.54, (male 61.86, female 17.65), Vitality 46.92 (male 48, female 46.47), MH 62.67 (male 74.29, female 57.88), SF 67.96 (male 84.14, female 61.29), pain 40.92 (male 51, female 36.76), and GH 43.13 (male 52.14, female 39.41) (Table 4).

Further statistical analysis was done for any association between the HRQoL components and sociodemographic factors and co-morbidity and treatment i.e. disease (yes/no) and treatment (yes/no) and where relevant significant differences were found for: i) $\mathrm{PF}$ with socio-demographic: gender (highly significant, $p<0.01)$ alcohol/beer/local beverage drinking (significant $p<0.01$ ), membership in association (significant, $p<0.05$ ), and co-morbidity and treatment: bone and joint pain or arthritis (significant, $p<0.05$ ) and treatment (significant, $p<0.05$ ), hearing impairment (significant, $p<0.05$ ) and treatment (significant, $p<0.05$ ); ii) RM with socio-demographic: gender (significant, $p<0.05$ ); iii) vitality with co-morbidity and treatment: bone and joint pain or arthritis (significant $p<0.05$ ); iv)
MH with socio-demographic: smoking (significant, $p<0.05)$; v) $\mathrm{SF}$ with socio-demographic: gender (significant, $p<0.05$ ) and marital status - currently living with spouse (significant, $p<0.05$ ), and comorbidity and treatment: bone and joint pain or arthritis (significant $p<0.05$ ) and treatment (significant, $p<0.05$ ); vi) pain with co-morbidity and treatment: arthritis (highly significant $p<0.01$ ) and treatment (significant, $p<0.05$ ); and vii) $\mathrm{GH}$ with socio-demographic : alcohol/ beer/local beverage drinking (significant $p<0.01$ ), comorbidity and treatment; bone and joint pain or arthritis (highly significant, $p<0.01$ ) and treatment (highly significant, $p<0.01$ ) (Table 5).

\section{Discussion}

Understanding variation and relationships among socio -demographic factors are increasing epidemiological interest in studying the effects of contextual and geographical factors on health disparities. ${ }^{25}$ In our study, the common socio-demographic findings were mean (sd) age: 67.71 (6.95) years old and similar for both male and female elderly, gender: male-female ratio (41\%: 7/17) which is greater than the national level elderly male-female ratio $(91 \%)$ as reported in the 2003 Malaysian report on the socio-economic characteristic of the elderly. ${ }^{2}$ Furthermore, illiteracy level of $95.8 \%$ was higher than the national level of $51 \%,{ }^{2}$ which could be explained by the remoteness of the rural villages in the studied area and the lower education rate in Sabah in which $21 \%$ of population had never attended school, as compared to the national statistics whereby $10 \%$ of population had never attended school. $^{26}$ Generally, those with higher

Table 4: Health-Related Quality of Life (SF-36) Eight Domains

\begin{tabular}{|c|c|c|c|}
\hline SF-36 Component Scoring & Male & Female & Total \\
\hline SF-36 Physical Functioning (PF) & 78.57 & 49.59 & 55.21 \\
\hline SF-36 Role Limitation due to Physical Health (RP) & 39.29 & 29.41 & 32.29 \\
\hline SF-36 Role Limitation due to Emotional Problems (RM) & 61.86 & 17.65 & 30.54 \\
\hline SF-36 Energy Fatigue (Vitality) & 48.0 & 46.47 & 46.92 \\
\hline SF-36 Emotional Well-Being (Mental Health-MH) & 74.29 & 57.88 & 62.67 \\
\hline SF-36 Social Functioning (SF) & 84.14 & 61.29 & 67.96 \\
\hline SF-36 Bodily Pain & 51.0 & 36.76 & 40.92 \\
\hline SF-36 General Health $(\mathrm{GH})$ & 39.41 & 52.14 & 43.13 \\
\hline
\end{tabular}

Table 5: Association between socio-demographic factors, and co-morbidity and health-related quality of life (SF-36) eight domains among respondents*

\begin{tabular}{|c|c|c|c|c|c|c|c|c|}
\hline Factors & $\mathbf{P F}$ & RP & $\mathbf{R M}$ & Vitality & MH & SF & Pain & GH \\
\hline Gender $(\mathrm{M} / \mathrm{F})$ & .009 & .494 & .019 & .664 & .055 & .034 & .260 & .087 \\
\hline Smoking status: current smoker $(\mathrm{Y} / \mathrm{N})$ & .066 & .271 & .052 & .122 & .023 & .271 & .401 & .271 \\
\hline Drinking alcohol/beer/local beverage: current drinking $(\mathrm{Y} / \mathrm{N})$ & .004 & .259 & .709 & .931 & .472 & .096 & .064 & .002 \\
\hline Marital status: currently living with spouse $(\mathrm{Y} / \mathrm{N})$ & .106 & 1.000 & 1.000 & .490 & .106 & .016 & .081 & .052 \\
\hline Membership in association $(\mathrm{Y} / \mathrm{N})$ & .041 & .310 & .505 & .145 & .805 & .271 & .082 & .452 \\
\hline Bone and joint pain or arthritis $(\mathrm{Y} / \mathrm{N})$ & .012 & .347 & .953 & .025 & .215 & .010 & .004 & .001 \\
\hline Treatment of bone and joint pain or arthritis $(\mathrm{Y} / \mathrm{N})$ & .042 & .539 & .546 & .054 & .428 & .030 & .020 & .003 \\
\hline Hearing impairment $(\mathrm{Y} / \mathrm{N})$ & .013 & .528 & .120 & .320 & .490 & .153 & .490 & .192 \\
\hline Treatment of hearing impairment $(\mathrm{Y} / \mathrm{N})$ & .012 & .252 & .079 & .342 & .352 & .254 & .300 & .306 \\
\hline
\end{tabular}

Keys: Physical Functioning (PF), Role Limitation due to Physical Health (RP), Role Limitation due to Emotional Problems (RM), Energy Fatigue (Vitality), Emotional Well-Being (Mental Health-MH), Social Functioning (SF), Bodily Pain (Pain), General Health (GH), Male/Female (M/F), Yes/No (Y/N).

*Independent samples, significant level if $\mathrm{p}$ value $<0.05$, all significant factors reported, Mann-Whitney Test applied. 
educational levels could have better awareness of health and be more involved in cognitive activities such as reading and writing. Moreover, illiteracy, significantly related to malnutrition and a further risk for a poor health state, ${ }^{14}$ could affect upon the health status of studied elderly.

The study also found out that greater proportion of currently not living with spouse (all male and half of female elderly) which is higher than national level. ${ }^{2}$ Unfortunately, this study did not examine further subgroupings of marital status. A study of the institutional elderly in Malaysia showed a higher percentage of currently not married (about $80 \%$ in male and $90 \%$ in female), in which, it was greater than the result for this study. ${ }^{14}$ In a previous study in Malaysia, it was reported that several factors have prevented elderly people from enjoying leisure activities as well as having a better quality of life such as increasing age and related physical deterioration, illiteracy, health status and the existence of chronic illness, absence of a life partner and the absence of friends to do the activity together. ${ }^{27}$ Our study also reported a lower level of participation in community activities (overall 13\%). In addition, overall, $13 \%$ and male $29 \%$ were current smokers, in which it was lower than other studies in Malaysia; whereby smoking among institutional elderly was $16.3 \%$ and smoking among male over 60 years old was $35 \%$. $^{14,28}$

HRQoL for the elderly is related to health status and the existence of co-morbidity or chronic illness. ${ }^{5,27}$ The study also reported the five most common disease comorbidities for elderly in the study area: hypertension, bone and joint pain or arthritis, ulcer/gastric pain/ gastritis, vision impairment, and hearing impairment. Hypertension, diabetes and arthritis are the most common co-morbidity among the elderly in many studies. ${ }^{2,6,29-30}$ Unlike other studies, this study was done in rural villages and there was a higher prevalence of hearing and vision problems because there was limited access to treatment. Furthermore, a lower utilization of treatment provision for vision and hearing impairment $(25 \%)$ was found against $80 \%$ treatment for hypertension, arthritis and gastric pain/gastritis. Vision and hearing impairment could be less serious, which could be the reason for elderly people did not seek treatment. However, vision and hearing were important for daily functioning and communication of elderly and the availability of hearing and vision treatment services in a primary-care setting and rural health centres should not be ruled out.

In this study, the average mean score for HRQoL domains varied from the highest HRQoL group scored; SF 67.96 and $\mathrm{MH}$ 62.67, medium HRQoL group scored; PF 55.21, Vitality 46.92, GH 43.13, and the lowest HRQoL group scored; Pain 40.92, RP 32.29, RM 30.54. A similar trend was found among community-dwelling elderly in Brazil, where the highest HRQoL score was SF (83.13) and the lowest HRQoL score was Pain (69.7). ${ }^{30}$ However, the Brazilian study had $100 \%$ literacy and $65 \%$ participation in social group activities among the participating elderly which were higher than our study.

In the past 30 years, many studies reported an association between socio-demographic factors and HRQoL. Lower HRQoL measures have been found among the elderly, women, ethnic minorities and people with the lowest socio-economic status. ${ }^{31-33}$ In our study, male elderly scored higher than that of female elderly for all eight HRQoL domains and statistically significant difference was found between gender and PF $(p<0.01)$, RM $(p<0.05)$, and SF $(p<0.05)$. Similar gender difference was found in other studies. A Malaysian study reported significant overall mean of HRQoL score for male and female and a Korea study showed significant difference for mean HRQoL scores of male and female for all domains. However, a French population-based study found that the HRQoL domain scores (except GH and Vitality) among 65-75-year-olds greater among males. $5,34,35$

Besides gender, other socio-demographic factors were also associated with HRQoL. Significant association was found for PF and membership in association $(p<0.05)$ and SF and marital status/currently living with spouse $(p<0.05)$. Social networking among elderly and the presence of friends are supportive factors for a better HRQoL among the elderly in two similar studies. ${ }^{27,36}$ Furthermore, a statistically significant association was also found for all eight HRQoL domains (SF-36) and marital status in a Korean study. ${ }^{5}$

Fostering good health is important for society in maintaining productivity of elderly. Studies showed that HRQoL for the elderly is limited by health status and the existence of chronic illnesses. ${ }^{5,27}$ Moreover, access to health treatment was also correlated with HRQoL, and among cancer patients, a statistically significant difference was found for mean HRQoL scores and access to treatment. ${ }^{37}$ In our study, two of five most common comorbidities were significantly associated with differences in five HRQoL domains: i) bone and joint pain or arthritis and PF $(p<0.05)$, Vitality $(\mathrm{p}<0.05), \mathrm{SF}(p<0.05)$, pain $(p<0.01)$ and GH $(p<0.01)$; treatment and $\mathrm{PF}(p<0.05)$, SF $(p<0.05)$, Pain $(p<0.05)$, and $\mathrm{GH}(p<0.05)$; and ii) hearing impairment and PF $(p<0.05)$; treatment and $\mathrm{PF}$ $(p<0.05)$. However, this study could not provide large enough sample size to detect difference among other co-morbidities and HRQoL domains. Jun et al. ${ }^{36}$ in the study of elderly Korean community reported a significant difference between HRQoL (EQ 5D) and diabetes $(p<0.01)$; however, hypertension $(p<0.08)$ and arthritis $(p<0.07)$ did not show any significant difference.

Pain and arthritis are chronic diseases which limit mobility in the elderly, not only to perform physical activity but also to socialize with friends. ${ }^{27,38-39}$ They are commonly related to a structural and functional deformity in the elderly which is important for individual daily activities such as drinking, eating, dressing, walking, toileting, gardening, washing, and so on. ${ }^{38-39}$ Furthermore, if a person suffers pain and 
debilitation, this leads to the inability to work and to enjoy life fully, with morbidity, disability, and a lower quality of life. ${ }^{38}$ Osteoporosis-related fractures have been recognized as a major health problem around the world, particularly in the elderly. ${ }^{39}$ According to the International Osteoporosis Foundation Report, ${ }^{39}$ the incidence of hip fractures in Malaysia among individuals above 50 years of age was 90 per 100,000 . Generally, hip fractures are associated with a high morbidity and mortality rate plus further disability resulting in only $25 \%$ patients able to resume normal activities. ${ }^{39}$ In our study, pain/arthritis is one of the most common co-morbidities, and pain/arthritis and treatment were significantly associated with HRQoL domains which- indicates the need for further exploration into the problem among the elderly and their effect on the HRQoL domains.

Hearing is important for the individual's ability to communicate with family members, relatives and others. Unfortunately, elderly people are often doubly burdened with both hearing impairment and poor vision, reported by the World Health Organization that eighty-two percentage of people living with blindness are over fifty years as well as one-third of people over sixty-five years are affected by disabling hearing loss, with the greatest prevalence in South Asia, Asia Pacific and Sub-Saharan Africa. ${ }^{40-41}$ Limited access to services and exclusion from communication can have a significant impact on daily life and HRQoL, especially for those older people with hearing loss, and these lead to a further exacerbation of feeling loneliness, isolation and frustration. In our study, hearing impairment and treatment were significantly associated to physical functioning domain in HRQoL. Further understanding of the relationship between the level of hearing and the duration of hearing impairment and HRQoL domains is needed.

This was a cross-sectional observation and provided an association between variables, however; a crosssectional study could not verify changes in the effects of the variables. This study explored remote Sabah elderly populations' HRQoL by a purposive sampling though it did not represent the whole country elderly population. Furthermore, various confounding factors are needed to examine for true effect of relationship of HRQoL and variables.

\section{Conclusion}

The world elderly population is rapidly increasing. Moreover, the proportion of elderly in developing countries is rising more rapidly. However, most of developing countries are not ready to support the national health system to look after the elderly. Nevertheless, good care is important for promoting older people's health and quality of life. In our study, the highest HRQoL group scored were SF and $\mathrm{MH}$, and the lowest were Pain, RP and RM. There is a significant relationship between HRQoL domains and sociodemographic factors (gender, marital status, membership in association), and health condition (comorbidities and access to healthcare, bone and joint pain or arthritis and treatment, hearing impairment and treatment). The outcomes of this study highlighted the need for social support like participating in association and access to health care for rural elderly in future programme.Relevant agencies and authorities should organize relevant elderly-related programs and policies at various levels to improve the access to healthcare for the elderly in rural primary-care settings. We also recommend further studies to determine elderly HRQoL in rural, urban and institutional settings for understanding differences and need for future health care planning and interventions.

\section{Acknowledgement}

We acknowledge Universiti Malaysia Sabah, School of Medicine medical students from 2012 August health promotion groups i.e. group 3, 7 and 8 , and the communities from $\mathrm{Kg}$ Linayukan, Tongodon and Simuda for their supports and participations in this study. Lastly but not the least, we fully appreciate Professor Dr Kamarudin D Mudin and School of Medicine for their full supports throughout our research and writing.

\section{Conflict of interest}

The authors declare no conflict of interest.

\section{References}

1. World Health Organization. Global Health Observatory - Life expectancy: Life expectancy by country. http://apps.who.int/gho/data/ node.main.688?lang=en (accessed Dec 2015).

2. Mat R, Taha HM. Socio-economic characteristics of the elderly in Malaysia, 21st Population Census Conference, Kyoto Japan, 19-21 Nov, 2003.

3. World Health Organization. Active aging: A policy framework. Geneva: World Health Organization, 2002.

4. Ware JE, Sherbourne CD. The MOS 36-item short-form health survey (SF-36). I. Conceptual framework and item selection. Med Care 1992; 30 (6):473-83.

5. Kim HS, Harada K, Miyashita M, Lee EA, Park JK, Nakamura Y. Use of senior center and the health-related quality of life in Korean older adults. J Pre Med Pub Health 2011;44(4):14956.

6. Lin CC, Li CI, Chang CK, Liu CS, Lin $\mathrm{CH}$, Meng $\mathrm{NH}$, et al. Reduced health-related quality of life in elders with frailty: A cross-sectional study of community-dwelling elders in Taiwan. $J$ PLoS One 2011;6 (7):e21841.

7. Olsson IN, Runnamo R, Engfeldt P. Medication quality and quality of life in the elderly, a cohort study. Health Qlity Life Outcomes 2011;9: 95.

8. Medical Outcomes Study: Measures of Quality of Life Core Survey from RAND Health (RAND »Medical Outcomes Study). http:// 
www.rand.org/health/surveys tools/mos.html (accessed Dec 2015)

9. Ware JE, Gandek B. Overview of the SF-36 Health Survey and International Quality of Life Assessment (IQOLA) project. J Clin Epidemiol 1998;51:903-12.

10. Tsay SY, Chi LY, Lee CH, Chou P. Healthrelated quality of life as a predictor of mortality among community - dwelling older persons. Eur J Epidemiol 2007;22:19-26.

11. Stewart AL, Greenfield S, Hays RD, Wells K, Rogers WH, Berry SD, et al. Functional status and well-being of patients with chronic conditions: Results from the Medical Outcomes Study. J Am Med Ass 1989;262:907-13.

12. Ritvo PG, Fischer JS, Miller DM, Andrews H, Patty DW, LaRocca NG. Multiple Sclerosis Quality of Life Inventory - A User Manual. National Multiple Sclerosis Society: New York, 1997.

13. Selvaratnam DP, Bakar NA, Idris NAH. Economic well-being and morbidity of the elderly in Malaysia. J Mod Account Auditing 2010;6 (4):45-51.

14. Cheng ST, Ngoh HJ, Harith S. Prevalence of malnutrition among institutionalized elderly people in Northern Peninsular Malaysia: Gender, ethnicity and age-specific). Sains Malaysiana 2012;41(1):141-8.

15. Mchorney CA, Ware Jr JE, Lu JFR, Sherbourne CD. The MOS 36 Item Short Form Health Survey (SF-36) - 3, Tests of data quality, scaling assumptions, and reliability across diverse patient groups. Med Care 1994;32:40-66.

16. Ware Jr JE, Hays RD. Methods for measuring patient satisfaction with specific medical encounters. Med Care 1988;26:393-402.

17. Ware Jr JE, Snow K, Gandek B, Kosinski M. SF36 Health Survey Manual and Interpretation Guide. Boston, MA: New England Medical Center, The Health Institute, 1993.

18. Kagee A. Review of the SF-36 Health Survey. In: Plake BS, Impara, JC. The Fourteenth Mental Measurements Yearbook. Lincoln NE: Buros Institute of Mental Measurements, 2001.

19. SF-36 Survey Instrument and scoring instruction. (RAND » RAND Health » 36-Item Short Form Survey). http://www.rand.org/health/ surveys tools $/ \mathrm{mos} / \mathrm{mos}$ core 36 item.html (accessed Dec 2015).

20. Ware Jr JE, Kosinski M, Bayliss MS, McHorney CA, Roger WH, Reczek A. Comparison of methods for the scoring and statistical analysis of SF-36 health profile and summary measures: Summary of results from the Medical Outcomes Study. Med Care 1995;33(4 Suppl): AS264AS79.
21. McHorney CA, Ware Jr JE, Raczek AE. The MOS 36-item short-form health survey (SF-36): II. Psychometric and clinical tests of validity in measuring physical and mental health constructs. Med Care 1993; 31(3):247-63.

22. Ware Jr JE, Sherbourne CD. The MOS 36-item short-form health survey (SF-36). I. Conceptual framework and item selection. Med. Care 1992;30(6):473-83.

23. Pit SW, Schurink J, Nair BR, Byles J, Heller RF. Use of the short-form-36 health survey to assess quality of life among Australian elderly. Aus $J$ Ageing 1996;15(3):132-5.

24. Andresen EM, Gravitt GW, Aydelotte ME, Podgorski CA. Limitations of the SF-36 in a sample of nursing home residents. Age Ageing 1999;28(6):562-6.

25. Cummins S, Curtis S, Diez-Roux AV, Macintyre S. Understanding and representing 'place' in health research: A relational approach. Social Sci Med 2007;65(9):1825-38.

26. United Nation Development Programme (UNDP). Sabah's Human Development Progress and Challenges Report. Kuala Lumpur: Kuala Lumpur, 2007.

27. Minhat HS, Md Amin $\mathrm{R}$, Shamsuddin $\mathrm{K}$. Late-life leisure constraints among Malaysian elderly: A qualitative approach. Mal J Pub Health Med 2012;12(2):24-30.

28. Lim HK, Gazali SM, Kee CC, Lim KK, Chan YY, Teh HC, et. al. Epidemiology of smoking among Malaysian adult males: prevalence and associated factors. BMC Pub Health 201;13(8):110.

29. Ye J, Shim R, Garrett SL, Daniels E. Healthrelated quality of life in elderly black and white patients with cancer: Results from Medicare managed care population. Ethn Dis 2012;22:3027.

30. Panasewicz A, Pedersen SS, Veenhuis SJG, Oemrawsingh RM, Giessen WJVD, Geuns RJV, et al. Health-related quality of life in the elderly three years after percutaneous coronary intervention. Euro Interv 2013; 9:373-81.

31. Faria CD, Teixeira-Salmela LF, Nascimento VB, Costa AP, Brito ND, Rodrigues-De-Paula F. Comparisons between the Nottingham Health Profile and the Short Form-36 for assessing the quality of life of community-dwelling elderly. Rev Bras Fisioter 2011; 15 (5): 399-405.

32. Mackenbach JP, Kunst AE, Cavelaars AE, Groenhof F, Geurts JJ. Socioeconomic inequalities in morbidity and mortality in Western Europe. The EU Working Group on Socioeconomic Inequalities in Health. Lancet 1997;349(9066):1655-9.

33. Hemingway H, Nicholson A, Stafford M, Roberts R, Marmot M. The impact of socioeco- 
nomic status on health functioning as assessed by the SF-36 questionnaire: The Whitehall II Study. Am J Pub Health 1997; 87(9):1484-90.

34. Etienne A, Stephane R, Joel C. Worsening trends and increasing disparities in health-related quality of life: Evidence from two French population-based cross-sectional surveys, 19952003. Qual Life Res 2013; 22:13-26.

35. Farooqui M, Hassali MA, Knight A, Shafie AK, Farooqui MA, Saleem F, et al. Cross-sectional assessment of health-related quality of life (HRQoL) among patients with cancer in Malaysia. Asia Pac J Cancer Prev 2013;14:3021 $-7$.

36. Lim JT, Park JH, Lee JS, Oh J, Kim Y. The relationship between the social network of community-living elders and their health-related quality of life in Korean Province. J Prev Med Pub Health 2013; 46: 28-38.
37. Dorling D, Mitchell R, Pearce J. The global impact of income inequality on health by age: An observational study. BMJ 2007;335(7625):873.

38. World Health Organization. Musculoskeletal conditions affect millions. http://www.who.int/ mediacentre/news/releases/2003/pr81/en/ (accessed Dec 2015)

39. International Osteoporosis Foundation: The Asian Audit, Epidemiology, costs and burden of osteoporosis in Asia. Nyon: International Osteoporosis Foundation, 2009.

40. World Health Organization. Deafness and hearing loss. Fact sheet N³00. http:// www.who.int/mediacentre/news/releases/2003/ pr81/en/ (accessed Dec 2015).

41. World Health Organization. Visual impairment and blindness. Fact sheet $\mathrm{N}^{\circ} 282$ http:// www.who.int/mediacentre/factsheets/fs282/en/ (accessed Dec 2015). 